\title{
Phenotypic Plasticity and Adaptation in a Holometabolous Insect: The Chironomid Midge
}

\begin{abstract}
Athol John McLachlan
School of Biology, Newcastle University, Newcastle upon Tyne NEl 7RU, UK

Correspondence should be addressed to Athol John McLachlan, a.j.mclachlan@virgin.net

Received 16 August 2011; Accepted 28 September 2011

Academic Editors: M. Griggio and I. Krams

Copyright (๑) 2012 Athol John McLachlan. This is an open access article distributed under the Creative Commons Attribution License, which permits unrestricted use, distribution, and reproduction in any medium, provided the original work is properly cited.

Attention is currently shifting from a gene-centred view of evolution to a more phenotype-focussed one. Here, I attempt to test this new paradigm against a diverse and ecologically prominent taxon, the chironomid midge. I conclude that putting phenotypic and developmental flexibility at the forefront helps resolve some persistent difficulties in understanding the process of adaptation.
\end{abstract}

\section{Introduction}

One of the most interesting recent conceptual developments in ecology and evolutionary theory is the renewed emphasis on phenotypic plasticity, conditional alternative phenotypes, and development [1-4]. This is a notable departure from the gene-centred thinking which has dominated evolutionary biology from the rediscovery of Mendel's laws, through the modern synthesis, and up until the present day [4]. In the words of West-Eberhard, the chief proponent and architect of this emerging paradigm, the "theoretical incorporation of developmental plasticity calls for changes in thinking about virtually every major question of evolutionary biology, and resolves some of its most persistent controversies." Morris [5, page 238] expresses the same opinion "Claims for the primacy of the gene have distorted the whole of biology." These contrasting views of evolution and some of their profound consequences are summarised below.

The Gene-Centred View. Mutation $\rightarrow$ Genome change $\rightarrow$ Selection $\rightarrow$ Loss of genetical variability $\rightarrow$ New genotype $\rightarrow$ New phenotype $\rightarrow$ Evolution.

Environmentally Lead Evolution. Environmental induction $\rightarrow$ Change in gene expression $\rightarrow$ New phenotype $\rightarrow$ Selection $\rightarrow$ Increased variability $\rightarrow$ Evolution.

Although it has long been appreciated that the phenotypic expression of a gene or combination of genes is heavily influenced by the developmental environment, this fact has recently taken on far greater significance with the realization that inherited variation in phenotypic responses may play an important role in driving evolutionary change. Thus, in contrast to the gene-centred view of evolution (exemplified most notably by Dawkins and by Wilson $[6,7]$ ), where phenotypes change through the slow accumulation of advantageous mutations, the newly emerging paradigm suggests that significant phenotypic reorganization can occur through altered responses to the developmental environment such as the duplication of body parts, cross-sexual transfer of traits, or heterochrony. Such a view of adaptive evolution is by no means mutually exclusive with more traditional models of adaptation and can be considered as a broadening of our understanding of potential mechanisms of adaptive phenotypic change.

Awareness of the central place of the phenotype in evolution has become widespread in recent years and, although still arguably of peripheral interest to mainstream science, it is now reflected in both physiology [8] and ecology [9-14]. The place of phenotype-centred thinking in the history of ideas about natural selection has been succinctly reviewed by Vane-Wright [15]. However, as yet there have been few attempts to integrate the phenotypic view of evolution into standard models in evolutionary ecology.

This paper is an attempt to fill this gap and to reinterpret some well-known examples of adaptation from the phenotypic perspective. Specifically, I reexamine research on the morphology, life history, and behaviour of a common 
holometabolous insect, the chironomid midge, in the light of new insights on the role of phenotypic plasticity in the process of adaptation. In doing so, I aim to highlight existing knowledge gaps and outline opportunities for future research.

Chironomid midges are chosen as a case study for several reasons: (1) they show a range of structures and life-history traits that are well understood and which have been intensively investigated over the course of the 20th century, (2) they can be found in a wide range of habitats which are subject to dramatically different environmental conditions, and finally, (3) I have some research experience on this taxon, having been actively involved in studying their ecology, behavior, and evolution since the early 1960s. I include a range of examples to illustrate the origin of novel traits and phenotypic plasticity at different levels of organisation in both structure (polymorphisms) and behaviour (polyphenisms) and in both larva and adult and in the evolution of endemism. I will use each example to explore whether new insights or understandings can be gained through approaching the issues through the conceptual lens of phenotypic plasticity.

\section{2. "Gill" Polymorphisms during Development}

The development of ventral "gills" in the larvae of the fresh water dwelling Chironomus midge varies enormously under the natural range of salt concentrations encountered in their home waters (Figure 1).

This genus is a specialised invader of a wide variety of inland waters including saline lakes which characterise the inland waters of much, perhaps most, of the world [17-19]. Typically these habitats occur in closed drainage basins and hence act as giant evaporation dishes, concentrating salt over the centuries and sometimes reaching the level of saturated brine [20]. The basins thus present a range of salinities in the same habitat, depending on an erratic cycle of filling and drying, and can be considered as "natural laboratories" for the study of adaptive responses to salt concentrations.

Lake Chilwa in tropical Africa is one such lake and is inhabited by the larvae of the midge Chironomus transvaalensis in prodigious numbers. The so-called "gills" of these larvae are thought to be an adaptation for the regulation of the salt concentration in the haemolymph [21], and gill size has been shown to be directly correlated with salt levels in the environment [16]. This latter finding lends support to the hypothesis that these gills have an ionic regulatory function and furthermore suggests that physiological and morphological flexibility in the phenotype may exist within a single genotype since it seems unlikely that individuals with different genotypes are able to optimally distribute themselves across such a spatially and temporally unstable environment. In the laboratory study cited above, [16], larvae were reared from the eggs of a single mother, further reducing genotypic differences between individuals as an explanation of the phenotypic variability observed.

In this example, phenotypic plasticity can be viewed as an adaptive response to unpredictable salinity levels encoun-



Figure 1: The relationship between salt concentration and gill length in the larvae of Chironomus transvaalensis. Open circles: ratio of length of posterior prolegs (a) to length of ventral tubule (b). Black dots: ration of length of posterior prolegs (a) to length of anal papillae (c). Terminal abdominal segments 11 and 12 are shown, after McLachlan [16]. Salt concentration, on the $x$-axis, is given as conductivity; length $(\mathrm{mm})$ is on the $y$-axis.

tered during development, and by extension, plasticity itself may have been the target of natural selection. The variation in gill size is continuous, so what is observed here is not a series of discrete alternative phenotypes (polymorphism) as Figure 1 might suggest. Instead, I suggest that the observed variation is the consequence of a plastic response within individual larvae.

However, there remain several unanswered questions that can only be addressed through further experimentation. For example, it is not known whether gill size is reversible-do the hypertrophied gills of larvae reared at high salt concentration diminish in size when encountering a dilute medium? These environmental conditions would be encountered in the wild-for example, following heavy rain-and it would seem to be adaptive for a midge to vary the size of the gills. However, the ability to revert to a former morphology would only be anticipated to evolve if the physiological costs of transformation were outweighed by the benefits of more efficient salt regulation and, crucially, if the changes could occur with sufficient rapidity to track the temporal pattern of variation in salt concentration. In large lakes such as Chilwa, the temporal variations in salt concentration may be gradual and predictable. However, chironomids inhabiting small pools face a much more rapidly changing and unpredictable environment [22], where the physiological ability to phenotypically track the environment may be unable to keep pace with the rate of change. Clearly, further experimentation is required to resolve these fascinating issues. 


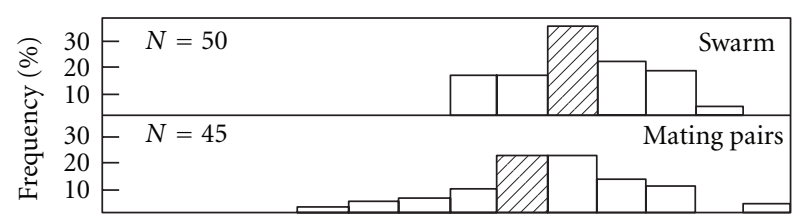

(a)

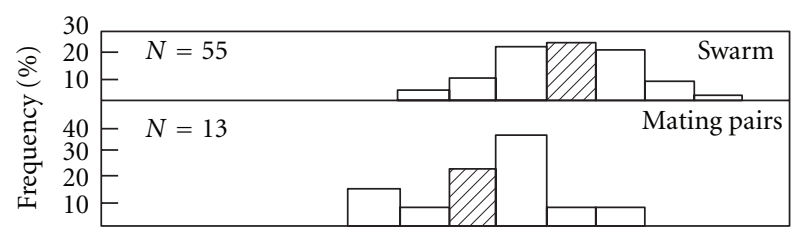

(b)

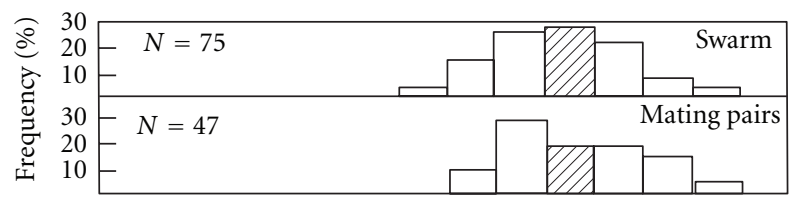

(c)

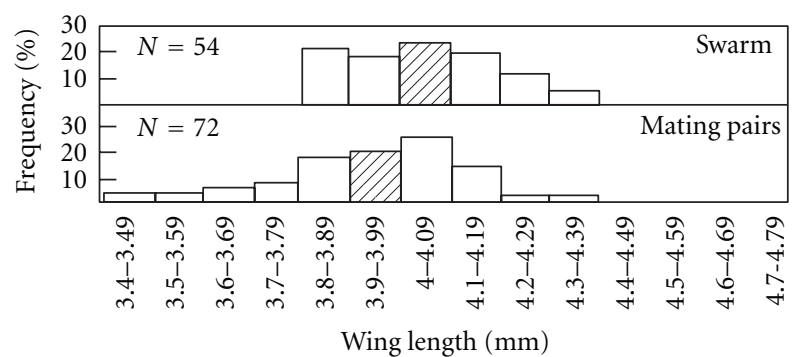

(d)

Figure 2: Size frequency distribution of C. plumosus males found in the swarm and in mating pairs in four replicate samples. The size class containing the mean is shaded, from [24].

\section{Size Polymorphism and Polyphenism in the Adult Male}

In the swarm-based mating system of chironomid midges [23], more is known of the biology of the adult male than the female, and hence this discussion pertains solely to the male fly. Within a mating swarm of males, there is considerable variation in body size. In one well-studied species, Chironomus plumosus, the smallest males are c. $20 \%$ smaller than the largest (Figure 2).

Ever since Charles Darwin's classical work [25], there is a tendency among evolutionary ecologists to equate large size in male animals to mating success. This is widely true, but where mating takes place in air, as it does here, small size has been shown to carry mating advantages through aerobatic superiority [26]. The phenotypic variability in body size may be maintained as a fitness trade-off with the larger males gaining through endurance [27], enabling them to stay in the swarm for longer. Smaller males may gain over the short term through aerobatic superiority, but lose mating opportunities when they have to drop out of the swarm to rest. Indeed, in at least two species, Ablabesmyia monilis and
Camptochironomus tentans, a discrete mode of very small individuals can sometimes be observed on the ground under the swam where they intercept arriving females before these enter the swarm [28], as in Figure 3.

So, as in the case of the $\alpha, \beta$, and $\gamma$ males seen in the marine isopod Paracerceis [29] and in fig wasps [30], there may be three discrete body size phenotypes in male chironomids. The fitness payoff is equal for $\alpha$ and $\beta$ males, but lower for $\gamma$ males who may be adopting the optimal strategy under the constraints of their exceptionally small body size. Alternatively, the $\gamma$ tactic could carry a higher fitness payoff because less energy is expended. Furthermore, $\gamma$ males have first access to females resting before entering the mating swarm.

What I need to know is whether this size polymorphism is genetically fixed or a flexible response to varying external conditions during larval development as discussed by WestEberhard [1, pages 421-422]. It has been suggested [31] that male polymorphism is under direct genetic control, with the proportion of the two morphs stabilised as an ESS. However, there is an alternative and so far unexplored hypothesis that is sufficient to account for the observed variation in morphology and behaviour. That is to say, variations in body size could be a flexible response to conditions during development acting on the same genotype. Thus, extreme environmental influences, such a poor nutrition or strong maternal effects, produce small males $(\beta)$ or even runts $(\gamma)$. If it is an EES, the proportions of the morphs will be consistent, if the result of a flexible genotype is responsive to environmental inputs, they will vary considerably between populations and sites. Unfortunately, such population data is currently lacking.

The $\gamma$ males are of particular interest, because it is possible to guess at the evolutionary origin of their adopted mating strategy. Since the swarm is required to attract females, the sit and wait behaviour of these males appears to be a form of kleptogamy, that is, the "parasitic" usurping of the mating effort of the $\alpha$ and $\beta$ males active in the swam. Furthermore, resting under the swarm is a female behaviour leading to the fascinating conjecture that this behaviour may have originated through cross-sexual transfer from the female-a potentially major but relatively unstudied mechanism for the evolutionary origin of novel phenotypes [1, pages 260-295].

\section{The Plastic Mating System: Polyphenisms Triggered by Parasites}

Swarm-based mating systems, reviewed by [32], are common among Diptera and include the smallest flying animalsthese can be so small that they encounter air as a viscous medium bringing with them interesting biomechanical problems [26, 33]. Mating swarms can be characterized as leks, that is, mating systems which involve one sex, usually the male, aggregating to display and compete for the attention of females. The males offer no resource to the females except sperm, yet female choice is, at least among the vertebrates, especially conspicuous. In the gene-centred 


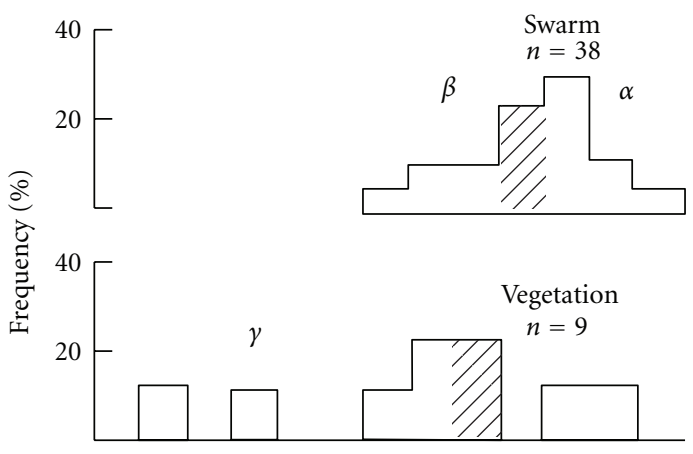

Wing length class

(a)

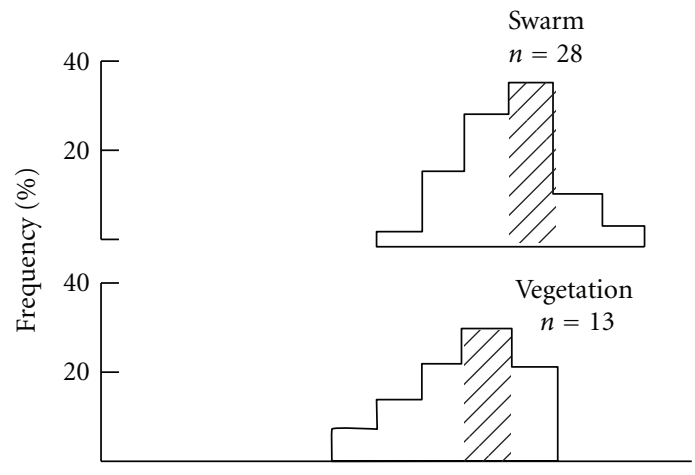

Wing length class

(c)

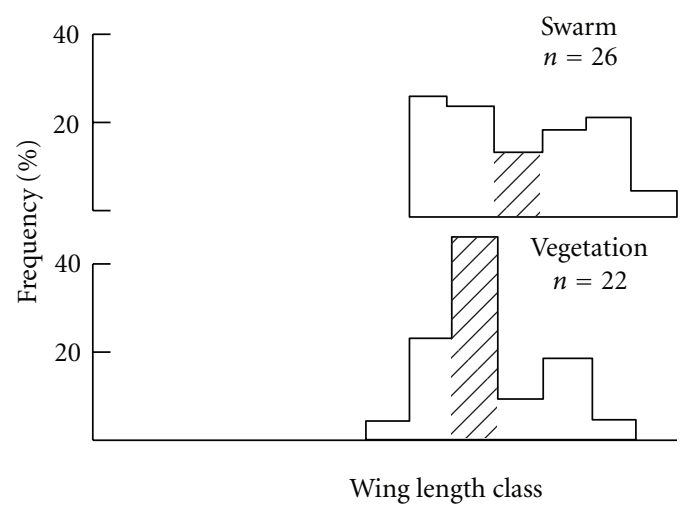

(e)

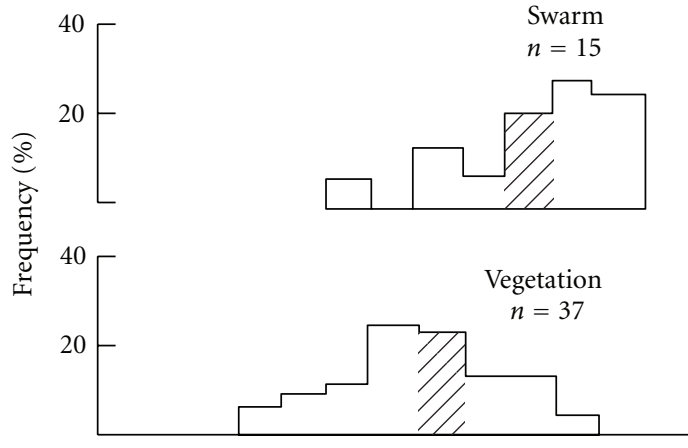

Wing length class

(b)

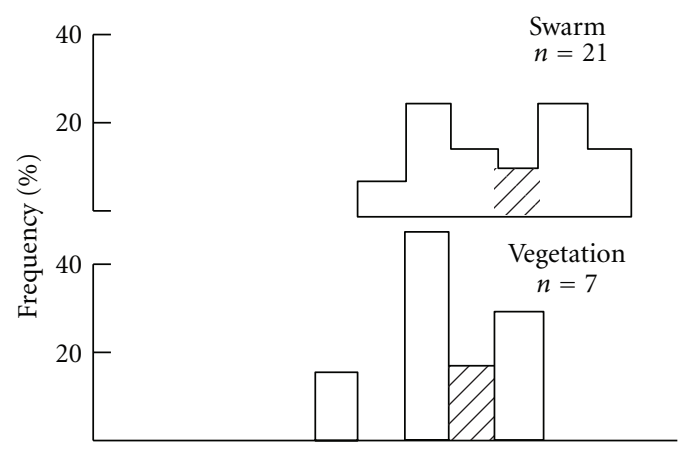

Wing length class

(d)

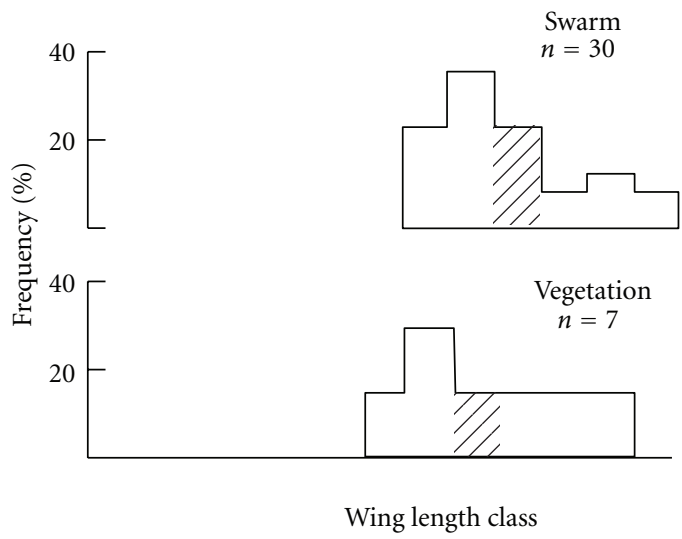

(f)

FIGURE 3: Size frequency distribution in six species of chironomid midge, in both male mating swarms and in vegetation under the swarm; $\alpha, \beta$, and $\gamma$ modes are indicated. Size classes are at intervals of $0.1 \mathrm{~mm}$, and those containing the mean wing length are shaded. Average size in swarms for each species is as follows: (a) Ablabesmyia monilis, $2.97 \mathrm{~mm}$; (b) Limnochironomus nervosus, $3.97 \mathrm{~mm}$; (c) Limnochironomus pulsus, $3.49 \mathrm{~mm}$; (d) Camptochironomus tentans, $6.39 \mathrm{~mm}$; (e) Psectrocladius barbimanus, $3.02 \mathrm{~mm}$; (f) Paragastiella orphila, $2.99 \mathrm{~mm}$. $n=$ number of flies measured, after McLachlan and Neems [23].

view, this process must inevitably lead to a depletion of the genetical variability upon which natural selection depends. Thus, in this traditional view, the evolution of the lek is somewhat paradoxical [34].

Swarm-based mating systems in general and chironomid midges in particular are well suited for the study of sexual selection. Like all holometabolous insects, once adulthood is achieved, individual chironomids do not grow, a character- istic beautifully encapsulated by Williams [35], "The earthbound early stages built enormous digestive tracts and hauled them around on caterpillar treads. Later in lifehistory these assets could be liquidated and reinvested in the construction of an essentially new organism-a flying machine devoted to sex." This fact removes a variable which confounds studies on vertebrates which grow continuously even after sexual maturity. Furthermore, adult chironomids 
do not need to feed, and the sole function of the adult is to reproduce. These two facts greatly simplify attempts to identify fitness components in the mating system and make holometabolous animals like chironomids a rational choice for studies of the evolution of mating systems.

Adult midges are prone to infection by at least two parasites, ectoparasitic hydracharinid mites and endoparasitic mermithid worms [1, page 265]. These parasites are large relative to their host (Figure 4) and may therefore perturb host aerobatics, upon which mating depends, through biomechanical load and drag effects.

Changes in mating behaviour due to the presence of the parasites can therefore be used as a natural experiment to probe the functioning of the mating system-uninfected individuals providing the control. Attention was first drawn to the importance of parasites on mating success of midges because, counterintuitively, both male and female host midges can experience an improvement in mating success when infected. Three seemingly conflicting lines of reasoning emerge from this observation.

(1) The apparent improvement in mating success of mite-infected males suggests that females may be attracted by the presence of a mite on the male. These mites are bright red in colour (Figure 5), and since Diptera appear to possess meta-absorbtion in the red part of the spectrum Doekele and Stavenga [37], a mite on a male midge might be perceived by the female as an attractive supernormal ancestral ornament.

The species most studied in this context is the common midge Paratrichocladius rufiventris [36, 38]. I note the species name "rufiventris" or "red belly" — possibly due to the typical presence of mites on museum specimens. Here, apart from affects on the female host in improved mating success, the mite gains because there is a chance during mating of transferring to the female host [39], and thus of returning to water to close its life cycle. Since it is only the female midge that returns to water, mites on a male midge potentially have zero fitness unless they can achieve such a transfer. So, in this sense, both parasite and female host could gain from infection.

(2) Evidence [39] suggests that mite-infected females gain in mating success as do the males in (1) above. This seemingly improved mating success of females could be the result of such females being slowed in a chase by a pursuing male. This explanation depends on biomechanical load and drag effects of the parasite making the female host more easily captured by the male. If this is true, it suggests that the mating system is based on sexual coercion with males pursing and overcoming reluctant females. It has been suggested that coercion may have evolved from the selective pressures imposed by predation rather than by sexual selection [40]. The involvement of natural selection in this way is an interesting possibility which remains to be tested for chironomids. In the case of these midges, a principal predator appears to be an Empid fly, see [33] for review. These predators are gift bearers, males entering midge swarms to capture midges as nuptial gifts for the Empid females. Here, there would be fitness advantages to female midges if escape flight evolved as a response to the approach of another fly. So, a pleiotropic advantage to predation avoidance might have led to the evolution of a mating system which rewards only the most agile, and hence also presumably the fittest males able to capture fleeing females. Thus, under a scenario of coercion, the midge mating system evolved as a form of sensory exploitation of a preexisting female bias against predators. This is a well-established principle in selection theory, reviewed by Ryan and Rand [41]. Furthermore, due to the life/dinner principle [42], predator-driven evolution could be rapid. This is because selective pressures are stronger on prey than predator since if the predator fails to achieve a capture, it loses only a meal, while if the prey is captured, it loses its life.

(3) When a second parasite, a mermithid worm Gastromermis sp., is present in the population of midges, mites are found almost exclusively on females lacking a worm [36]. Mermithids have a variety of effects on host sexuality, reviewed by West-Eberhard [1, page 265]. In the case of midges, worms render a female midge sterile and so reduce her fitness (and that of any male mating solely with her) to zero. So here is a reinforcing selective pressure for the male midge to mate with a female bearing a mite. This effect hinges on mate choice, but here males are the choosy sex and females bare the peacock's tail in the form of a mite.

To summarise, I assume that the three tantalizing possibilities are mutually exclusive, that is, mate choice by male (2), mate choice by female (1), and coercion by the male (3). But which of the three is correct? This conundrum can potentially be resolved by the application of phenotypecentred reasoning. What I suggest and I want to make a real point here is that the three mating systems may be interchangeable, involving switch points between alternative mating tactics like those suggested on theoretical considerations by Kokko and Rankin [43]. However, unlike their argument where switch points depend on population density, in the case of midges, switch points between alternative polyphenisms are, I suggest, triggered by parasites. In short, the midge mating system may illustrate phenotypic flexibility of mating behaviour depending on environmental input due to the presence of parasites.

This is a testable hypothesis. For example, based on the proportion of parasitized and unparasitized males and females in mating pairs, the confounding effect of mite presence on assortative mating can be illustrated as follows: if mating is random with respect to infection by mite (and is therefore not assortative by the presence of mite), mating pairs would be found with the following probabilities:

male infected $/$ female infected $=\mathrm{Mi} / \mathrm{Fi}$, male infected/female not infected $=\mathrm{Mi} /(1-\mathrm{Fi})$, 


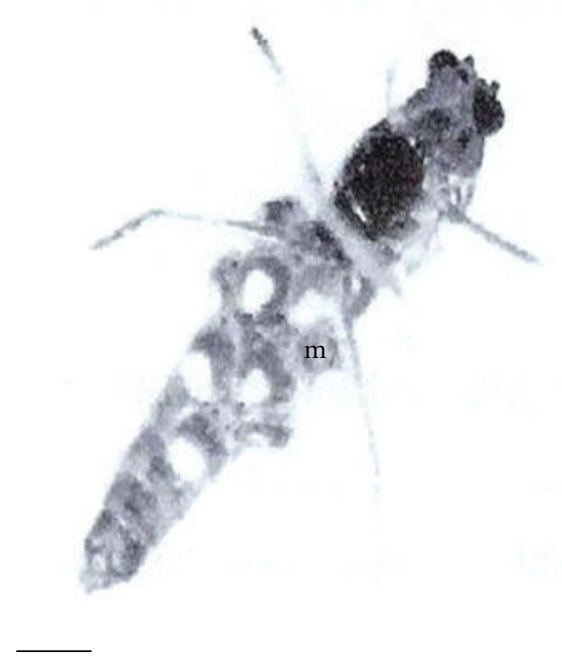

(a)

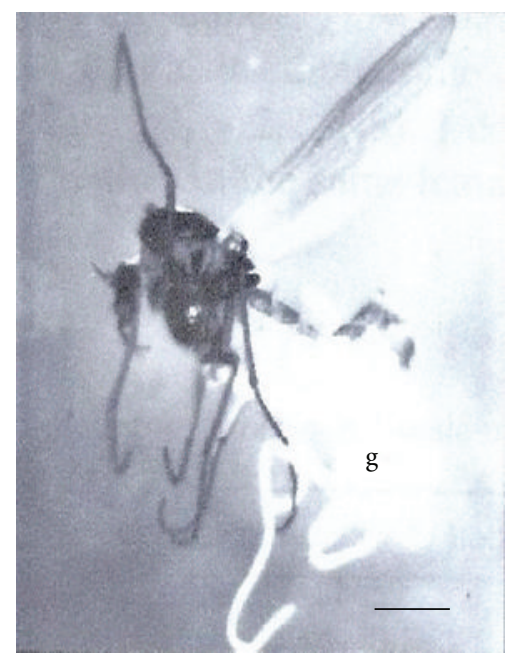

(b)

FIgURE 4: A female host midge, (a) infected with nine mites ( $\mathrm{m}$ ) and (b) infected with a worm ( $\mathrm{g}$ ) in the process of emerging from its host (scale bare $=0.5 \mathrm{~mm}$ ), from McLachlan [36].

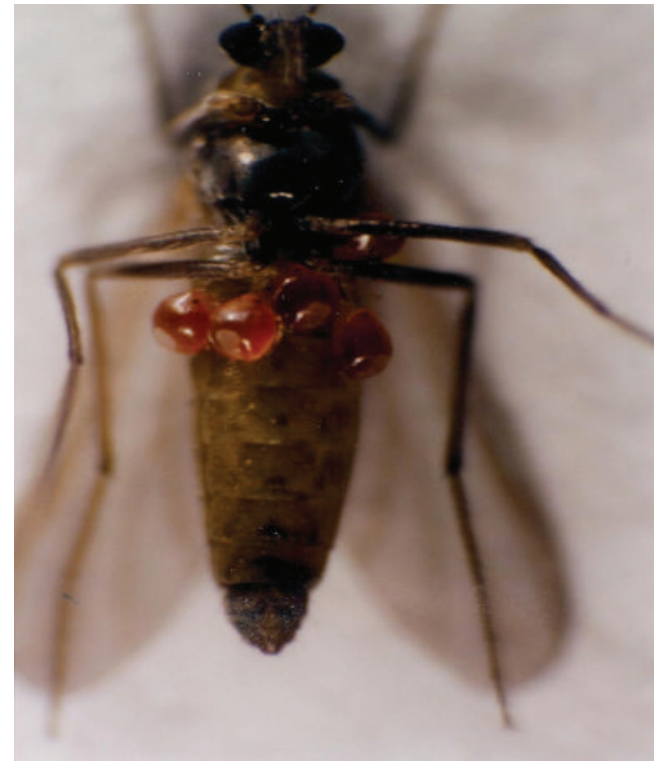

Figure 5: A female chironomid midge (Paratrichocladius rufiventris), with several bright red mites attached to her ventral surface (the female is c. $2 \mathrm{~mm}$ long), (photo by A. J. McLachlan).

male not infected/female infected $=(1-\mathrm{Mi}) / \mathrm{Fi}$,

male not infected/female not infected $=(1-\mathrm{Mi}) /$ $(1-\mathrm{Fi})$.

Inserting observed values into this model would provide expected values which can be tested for departure from random with Chi-Square goodness of fit. This test remains to be carried out.

\section{Phenotypic Plasticity and the Evolution of Endemism}

Rain pools on rock surfaces in tropical Africa have provided a useful model system for the study of adaptation [22]. They are inhabited by the larvae of one of three midge species, all indigenous to these pools and, so far, have been found in no other habitat. Furthermore, they occur at prodigious densities, facilitating statistically accurate sampling. Since a particular pool is consistently inhabited by the same species, year after year and probably for thousands or even millions of years, many adaptive questions can be addressed.

The point I wish to make here is that the case for endemism in these larvae may be flawed. It is conceivable that these three species are all present elsewhere but at such low densities that they are difficult to detect. I hesitate to make this suggestion as it seems unlikely to be applicable. If the adults of such a rare species cannot be detected by careful sampling, they are unlikely to find each other to breed. But such a scenario cannot be excluded on theoretical ground alone. Taking just the great lakes of Africa as a case in point, I made some first-approximation calculations which encourage the possibility that the major part of the gene pool for each of the species could theoretically exist in those giant lakes [44]. The conclusion reached at that time was that, in such a situation, natural selection would shape the phenotype in permanent waters rather than in the rain pools, so that survival in pools would be a matter of chance, and any apparent adaptation to the pools would be illusory.

This is a possibility that is seldom considered by evolutionary biologists. But there is another interesting consequence of this line of reasoning. I refer to the possibility that the extreme differences in the environments provided by large, effectively permanent lakes and small very transient pools would require an astonishing degree of phenotypic 
flexibility among inhabitants. In which case, phenotypic plasticity itself would have been the target of selection leading to a phenotype sufficiently flexible to survive and breed at both extremes of the home range. This is pure conjecture but is a testable hypothesis, strongly reminiscent of the work of Gause [45], on salt tolerance in Paramecium. Similarly, although much reduced flexibility is seen in some temporary waters where inhabitants of permanent waters are stranded after floods, they nevertheless are sufficiently plastic to survive and breed in the puddles where they are stranded by receding flood waters [45].

\section{Conclusions}

Through a series of case histories I have attempted to show that the application of phenotype-centred reasoning resolves many difficulties in understanding the biology of a taxon with which I am closely familiar. These four examples have been selected to present a wide variety of contrasting cases. There is no common theme. To highlight just one outcome, the long-standing paradox of the lek is circumvented (see paragraph one of Section 1). I point out where empirical tests are required, but that is not the main thrust of this paper. Rather, I seek the most plausible, the most rationally consistent explanation of observations. This is not to say that phenotype-centred thinking lacks empirical tests. On the contrary, it is exhaustively supported by evidence from a wide range of vertebrate and invertebrate examples, leading to what is essentially a new paradigm [1]. At a practical level too, such a change in emphasis has enormous advantages for field biologists who are not routinely able to carry out the careful rearing procedures necessary to identify genetical change upon which heritable changes are traditionally focussed.

\section{Acknowledgments}

The author acknowledges the contribution of John Lazarus in providing the framework for a test to distinguish between the three options cited in Section 4. He acknowledges also the input of Richard Ladle in bringing this paper to completion.

\section{References}

[1] M. J. West-Eberhard, Developmental Plasitcity and Evolution, Oxford University Press, Oxford, UK, 2003.

[2] M. J. West-Eberhard, "Phenotypic accommodation: adaptive innovation due to developmental plasticity," Journal of Experimental Zoology. Part B, vol. 304, no. 6, pp. 610-618, 2005.

[3] M. J. West-Eberhard, "Toward a modern revival of Darwin's theory of evolutionary novelty," Philosophy of Science, vol. 75, no. 5, pp. 899-908, 2008.

[4] M. J. West-Eberhard, "Darwinism in the twenty-first century," Rendiconti Lincei, vol. 20, no. 4, pp. 297-299, 2009.

[5] C. S. Morris, Life's Solutions: Inevitable Humans in a Lonely Universe, Cambridge University Press, Cambridge, UK, 2003.

[6] R. Dawkins, The Selfish Gene, Oxford Clarendon Press, Oxford, UK, 1976.

[7] E. O. Wilson, Consilience: The Unity of Knowledge, Knopf, New York, NY, USA, 1998.
[8] M. R. Alexander, Optima for Animals, Princeton University Press, Princeton, NJ, USA, 1994.

[9] J. Stamps, "Behavioural processes affecting development: tinbergen's fourth question comes of age," Animal Behaviour, vol. 66, no. 1, pp. 1-13, 2003.

[10] F. Aubret, R. Shine, and X. Bonnet, "Adaptive developmental plasticity in snakes," Nature, vol. 431, no. 7006, pp. 261-262, 2004.

[11] J. C. Crighton, "Population density, body size, and phenotypic plasticity of brood size in a burying beetle," Behavioural Ecology, vol. 16, pp. 1030-1036, 2005.

[12] A. R. Palmer, "Evolutionary biology: caught right-handed," Nature, vol. 444, no. 7120, pp. 689-692, 2006.

[13] A. Bird, "Perceptions of epigenetics," Nature, vol. 447, no. 7143, pp. 396-398, 2007.

[14] E. C. Tumer and M. S. Brainard, "Performance variability enables adaptive plasticity of "crystallized" adult birdsong," $\mathrm{Na}$ ture, vol. 450, no. 7173, pp. 1240-1244, 2007.

[15] R. I. Vane-Wright, "Whatever happened to the organic selectionists?” Antenna, vol. 35, pp. 57-60, 2011.

[16] A. J. McLachlan, "Variation of 'Gill' size in the larvae of the African midge Chironomus transvaalensis Kieffer," Journal of the Limnological Society of southern Africa, vol. 2, pp. 55-56, 1976.

[17] I. A. E. Bayly, "The general biological classification of biological environments with special reference to those in Australia," in Australian Inland Waters and Their Faunas: Eleven Studies, A. H. Weatherly, Ed., pp. 78-104, National University Press, Canberra, Australia, 1967.

[18] M. Kalk, A. J. McLachlan et al., Lake Chilwa: Studies of Cahnge in a Tropical Ecosystem, Dr. W. Junk, London, UK, 1979.

[19] W. D. Williams, "1. Inland salt lakes: An introduction," Hydrobiologia, vol. 81-82, no. 1, pp. 1-14, 1981.

[20] L. C. Beadle, The Inland Waters of Tropical Africa, Longman, London, UK, 1974.

[21] F. S. Strenzke, "Die systematisches und okologische Differenzierung der Gattung Chironomus," Annales Entomologicae Fennicae, vol. 26, pp. 111-138, 1960.

[22] A. Mclachlan and R. Ladle, "Life in the puddle: behavioural and life-cycle adaptations in the Diptera of tropical rain pools," Biological Reviews, vol. 76, no. 3, pp. 377-388, 2001.

[23] A. McLachlan and R. Neems, "An alternative mating sysem in small male insects," Ecological Entomology, vol. 14, no. 1, pp. 85-91, 1989.

[24] R. M. Neems, A. J. McLachlan, and R. Chambers, "Body size and lifetime mating success of male midges (Diptera: Chironomidae)," Animal Behaviour, vol. 40, no. 4, pp. 648-652, 1990.

[25] C. Darwin, The Descent of Man and Selection in Relation to Sex, The Modern Library, Random House, New York, NY, USA, 1959.

[26] B. Crompton, J. C. Thomason, and A. McLachlan, "Mating in a viscous universe: the race is to the agile, not to the swift," Proceedings of the Royal Society B, vol. 270, no. 1528, pp. 19911995, 2003.

[27] R. M. Neems, J. Lazarus, and A. J. McLachlan, "Lifetime reproductive success in a swarming midge: trade-offs and stabilizing selection for male body size," Behavioral Ecology, vol. 9, no. 3, pp. 279-286, 1998.

[28] A. J. McLachlan and D. F. Allen, "Male mating success in Diptera: advantages of small size," Oikos, vol. 48, pp. 11-14, 1987.

[29] S. M. Shuster and M. J. Wade, "Equal mating success among male reproductive strategies in a marine isopod," Nature, vol. 350, no. 6319, pp. 608-610, 1991. 
[30] J. C. Moore, J. Pienaar, and J. M. Greeff, "Male morphological variation and the determinants of body size in two Otiteselline fig wasps," Behavioral Ecology, vol. 15, no. 5, pp. 735-741, 2004.

[31] A. J. McLachlan, "Animal populations at extreme densities: size dimorphism by frequency dependent selection in ephemeral habitats," Functional Ecology, vol. 3, no. 5, pp. 633-643, 1989.

[32] A. J. McLachlan and R. M. Neems, "Swarm based mating systems," in Insect Reproduction, S. R. Leather and J. Hardie, Eds., CRC Press, New York, NY, USA, 1995.

[33] A. McLachlan, R. Ladle, and B. Crompton, "Predator-prey interactions on the wing: aerobatics and body size among dance flies and midges," Animal Behaviour, vol. 66, no. 5, pp. 911915, 2003.

[34] M. Andersson, Sexual Selection, Princeton University Press, Princeton, NJ, USA, 1994.

[35] C. M. Williams, "Hormonal regulation of insect metamorphosis," in Symposium on the Chemical Basis of Development, W. D. McElroy and B. Glass, Eds., pp. 794-806, John Hopkins University Press, Baltimore, Md, USA, 1958.

[36] A. J. McLachlan, "You are looking mitey fine: parasites as direct indicators of fitness in the mating system of a host species," Ethology Ecology and Evolution, vol. 18, no. 3, pp. 233-239, 2006.

[37] G. Doekele and D. G. Stavenga, "Pigments in compound eyes," in Facits of Vision, D. G. Stavenga and R. C. Hardie, Eds., Springer, London, UK, 1989.

[38] A. J. McLachlan, T. W. Pike, and J. C. Thomason, "Another kind of symmetry: are there adaptive benefits to the arrangement of mites on an insect host?" Ethology Ecology and Evolution, vol. 20, no. 3, pp. 257-270, 2008.

[39] A. McLachlan, "Parasites promote mating success: the case of a midge and a mite," Animal Behaviour, vol. 57, no. 6, pp. 1199 1205, 1999.

[40] G. Arnqvist, "Sensory exploitation and sexual conflict," Philosophical Transactions of the Royal Society B, vol. 361, no. 1466, pp. 375-386, 2006.

[41] M. J. Ryan and A. S. Rand, "Sexual selection and signal evolution8212; the ghost of biases past," Philosophical Transactions. Royal Society of London, B, vol. 340, no. 1292, pp. 187-195, 1993.

[42] J. R. Krebs and N. B. Davies, An Introduction to Behavioural Ecology, Blackwell Scientific Publications, London, UK, 1981.

[43] H. Kokko and D. J. Rankin, "Lonely hearts or sex in the city? Density-dependent effects in mating systems," Philosophical Transactions of the Royal Society B, vol. 361, no. 1466, pp. 319334, 2006.

[44] A. J. McLachlan, "Refugia and habitat partitioning among midges (Diptera: Chironomidae) in rain-pools," Ecological Entomology, vol. 13, no. 2, pp. 185-193, 1988.

[45] G. F. Gause, "The relationship of adaptability to adaptation," Quarterly Review of Biology, vol. 17, pp. 99-114, 1942. 



Submit your manuscripts at

http://www.hindawi.com

Signal ${ }^{\text {Jumal }}$ Transduction
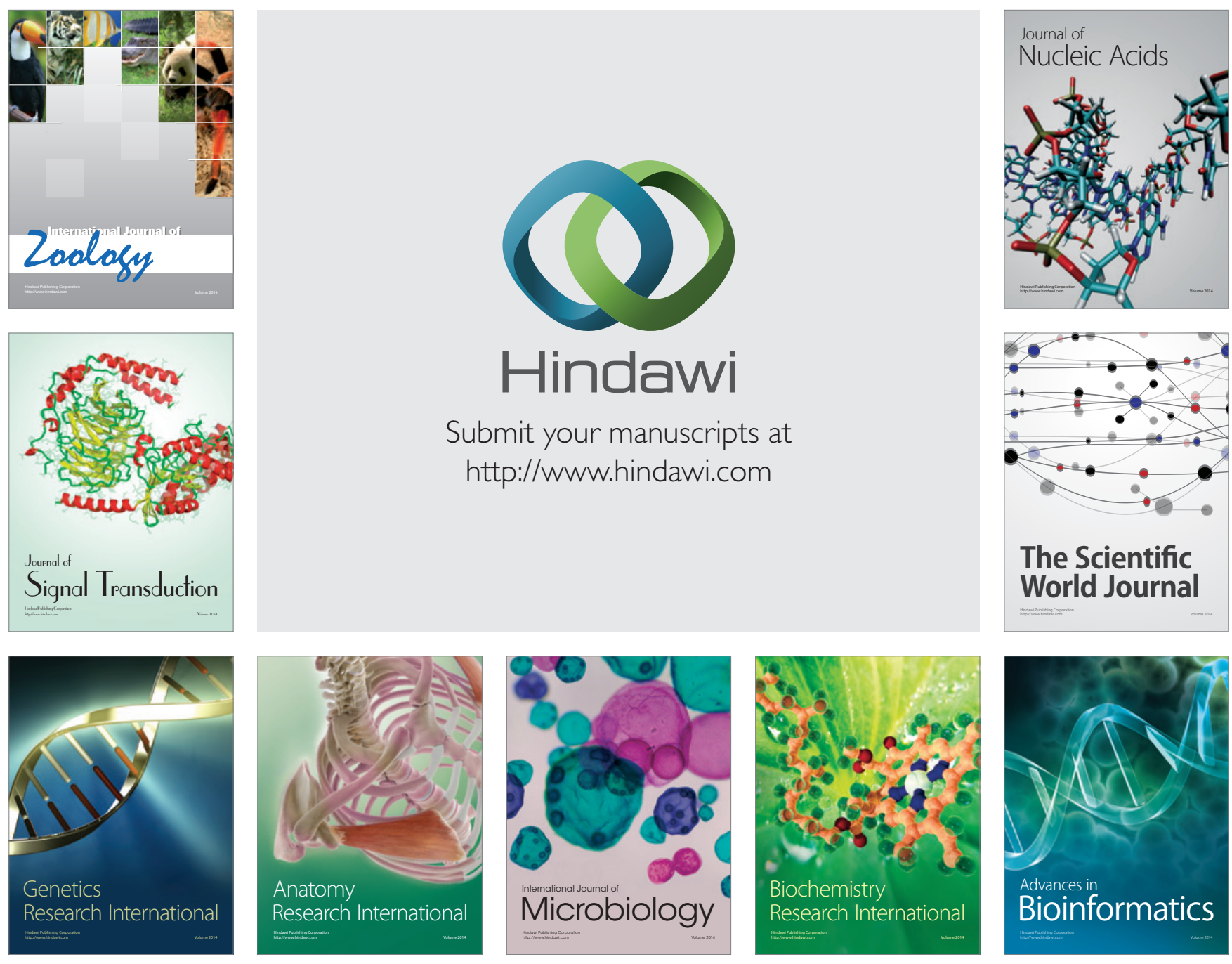

The Scientific World Journal
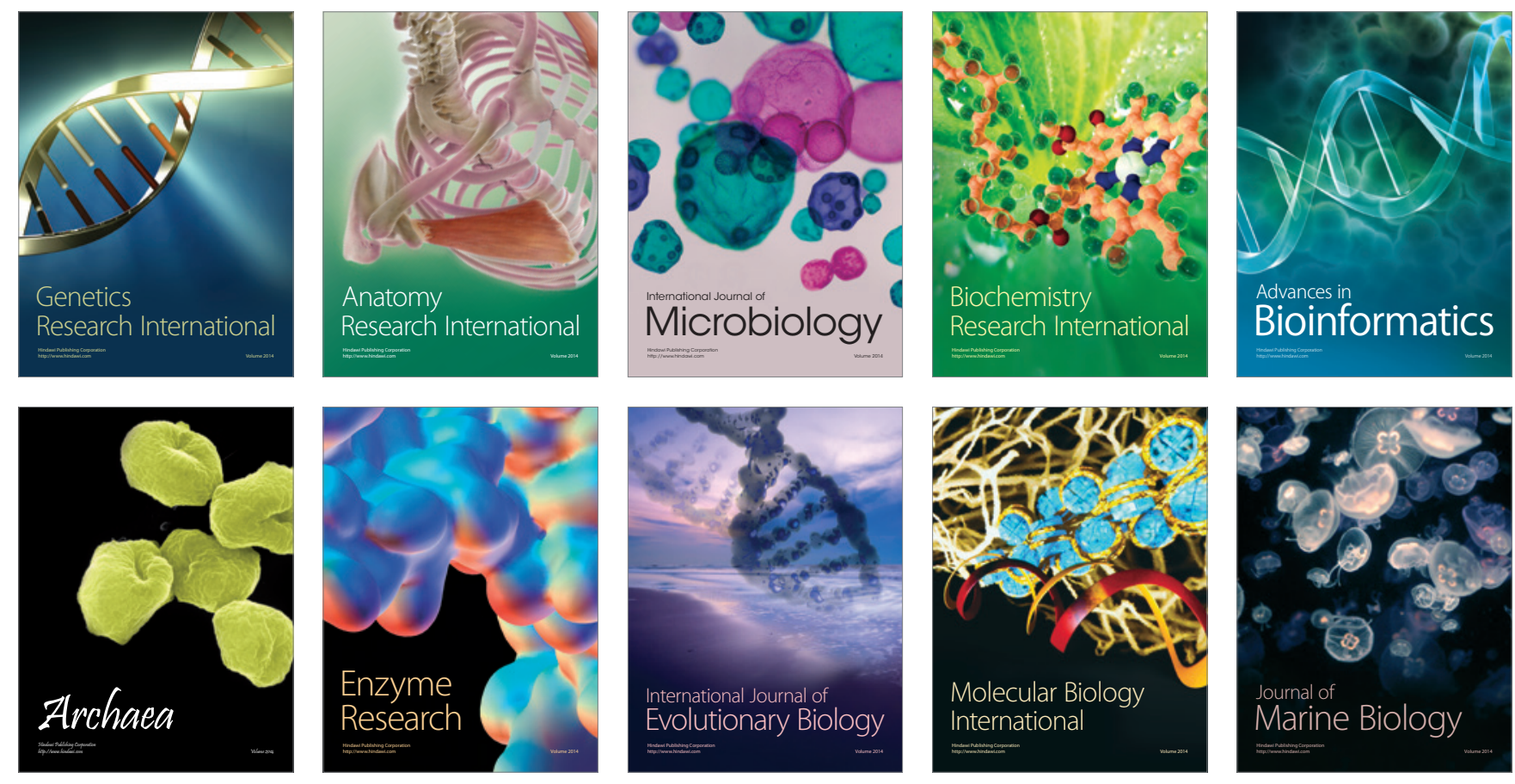